\title{
What's wrong with UNESCO
}

\author{
The new director-general needs to buck all expectations and transform the agency.
}

$\Lambda$ s Nature went to press, Irina Gueorguieva Bokova, a Bulgarian diplomat, and Farouk Hosny, Egypt's minister of culture, faced off in a final electoral round to become director-general of the United Nations Educational, Scientific and Cultural Organization (UNESCO). The vote, by the agency's executive board, is subject to confirmation in October by its general conference.

The election highlights UNESCO's faults. The agency publishes a list of the candidates' names, but nothing on their qualifications or vision for the agency. In truth, nominations and the secret voting are largely down to horse-trading among member states.

Such anachronistic processes need to change, but so does much else at this suffocatingly bureaucratic organization. An independent review of UNESCO's science portfolio in 2007 reached the damning conclusion that "UNESCO has over time lost its leadership credibility as an international spokesman for science, and its programmes are now seen by the scientific community as fragmented, over-ambitious, unfocused and lacking a clear vision and scientific strategy".

That should have been a wake-up call. But the panel's suite of recommendations, including prioritizing and refocusing the agency's science activities, and establishing an advisory committee of outside scientists reporting to the director general (see http://tinyurl.com/ unesco-science), met with a defensive response. The agency rejected the idea of an expert committee, while implementation of the panel's other recommendations (http://tinyurl.com/unesco-genconf) does not go far enough. Business as usual continues.

UNESCO's science section has an annual regular budget of around US\$55 million and 160 staff. It needs to focus its efforts on a few areas where it might make an impact. With science-based issues now omnipresent throughout the United Nations (UN) and many other international agencies, UNESCO must slash everything superfluous, such as its puny programme on renewable energy.

UNESCO has strengths to build on. Its water programme is large and flabby, but outside scientists rate some parts of it highly, such as the International Hydrological Programme on water research and management. These should be reinforced and integrated with the activities of the two dozen other UN agencies that work on water Too often, UNESCO's science programmes are isolated from related work elsewhere, and even from its own social science, education, and culture arms. The agency also has an important resource in its network of national offices, and UNESCO-branded field centres such as biosphere reserves and science labs, where many potential synergies, for example for ecological monitoring, are under-exploited.

Yet despite its shortcomings, UNESCO is uniquely placed in being the only UN agency with an explicit mandate to promote science. And its intergovernmental status, although often a handicap, potentially gives it the power to convene the world's best expertise to take forward important agendas.

UNESCO has made a start along those lines. Its advice to Nigeria on building a science system is credited as a factor in the Nigerian government's $\$ 5$ billion commitment to science in 2006. UNESCO has the potential to become a leader in such areas, providing policy analysis and benchmarking for less scientifically advanced countries. This seems a better road to promoting infrastructure than its current smattering of tiny grants in its International Basic Sciences Programme. UNESCO should give up the hopeless notion that it can be a research funder, and focus on policy and leverage.

The outgoing director general Kö̈chiro Matsuura, a Japanese diplomat, has reformed UNESCO's finances and recruitment practices. But he brought little vision or change to the science programme. His successor should take the 2007 review as the starting point for a rootand-branch review of the science programme, persuade the member states to weed out all activities that have little or no impact and create a culture of performance, transparency and evaluation. An upcoming wave of retirement at the agency provides an opportunity to bring in fresh blood.

The history and culture of UNESCO do not bode well for serious change. But business as usual is not an option if UNESCO is to have a scientific raison d'être.

\section{Earth's boundaries?}

\section{An attempt to quantify the limits of humanity's load on our planet opens an important debate.}

n this issue of Nature, a group of renowned Earth-system and environmental scientists led by Johan Rockström of the Stockholm Resilience Centre sets out to define boundaries for the biophysical processes that determine the Earth's capacity for self-regulation (see page 472). The framework presented is an attempt to look holistically at how humanity is stressing the entire Earth system. Provocatively, they go beyond the conceptual to suggest numerical boundaries for seven parameters: climate change, ozone depletion, ocean acidification, biodiversity, freshwater use, the global nitrogen and phosphorus cycles, and change in land use. The authors argue that we must stay within all of these boundaries in order to avoid catastrophic environmental change.

The boundaries are based on existing data. For some processes, such as anthropogenic climate change and human modification of the nitrogen cycle, we may already have crossed the line, and need to back-pedal quickly. For others, such as ocean acidification, we are rapidly approaching a threshold beyond which there may be abrupt and nonlinear changes.

The exercise requires many qualifications. For the most part, the exact values chosen as boundaries by Rockström and his colleagues 